\title{
Effect of Using Clinical Pathway on Nursing Care For Neonates with Sepsis
}

\author{
Amel Abd-Elaziz Abd-Elsalam ${ }^{1}$, Seham Mohammed Abd-Elaziz ${ }^{2}$ \\ ${ }^{12}$ Lecturer of Pediatric Nursing, Faculty of Nursing, Benha University, Egypt
}

\begin{abstract}
Early identification and implementation of the sepsis protocol/pathway will provide positive outcomes for neonates cared for at neonatal intensive care unit. The quality of care rendered will be positively affected by having a standard protocol/pathway. The aim of this study was to determine the effect of clinical pathway on nursing care for neonates with sepsis. A quasi-experimental design was used. This study was carried out at neonatal intensive care units affiliated to Benha University Hospital and Benha specialized hospital of children and Benha Teaching Hospital at Benha city. A convenient sample of (140) nurses and all the available neonates with sepsis (140 neonates). Three tools were used; Tool I- A structured interviewing schedule, which consists of four parts: Nurses' characteristics, neonates' characteristics, Nurses' knowledge regarding neonatal sepsis, and Nurses' Knowledge about nursing care for neonates with sepsis. Tool II- Clinical pathway of care checklist. Tool III-Neonatal clinical outcome assessment sheet. Results of this study revealed that, there were statistically significant differences regarding the effect of clinical pathway on the clinical outcomes of studied neonate's pre and post clinical pathway implementation. This study concluded that: Implementation of the clinical pathway improved nurses' knowledge and practice that reflecting obvious improvement in clinical outcomes of neonates with sepsis. The study recommended that: Clinical pathway on nursing care of neonates with sepsis should be applied for neonates with sepsis at different settings.
\end{abstract}

Key words: Clinical pathway, nursing care, sepsis.

\section{Introduction}

Sepsis is a toxic condition caused by the spread of invading organisms, or their by-products, through the bloodstream or in other tissue in the body. It is also known as septicemia. The definition of sepsis has evolved beyond that of an infection. There is now a spectrum of symptoms of systemic inflammatory response syndrome (SIRS) to septic shock (Shankar-Hari et al., 2016). Causes of sepsis include viral, fungal, bacterial or parasitic in nature.

Neonatal sepsis differs from adult sepsis in terms of symptoms, diagnosis and treatment, and continues to have a high rate of morbidity and mortality for infants. Neonatal sepsis occurs within the first 30 days of life, although some late-onset sepsis has been described within the first 90 days of life, particularly when related to prematurity (Singer et al., 2016).
Sepsis is a widespread bacterial infection in the blood circulation. It is also referred to as septicemia. Infants are at high risk of infection due to their low and immature immune system. The newborn has a poor response to pathogens and the local inflammatory reaction that signals the presence of an infection at the entry site is usually absent, which results in non-specific and broad symptoms. Subsequently, making the correct diagnosis and implementing a treatment is often delayed (National Institute for Health and Care Excellence, 2016).

Neonatal sepsis or sepsis neonatarum is an infection that can be attracted in the prenatal period through vertical transmission from the mother bloodstream or during the delivery period from ingestion of infected amniotic fluid. The literature distinguishes two types of neonatal 
sepsis, early onset and late onset (Casserly et al., 2015).

Early-onset sepsis is classified as occurring in newborns less than 72 hours of age. Approximately 1 to 8 out of every 1000 births results in earlyonset sepsis. The causes of infection for early-onset sepsis occur from maternal transmission during pregnancy or delivery, or immediately following delivery. Symptoms may be present at birth, but many infants demonstrate symptoms in the first 24 hours of life (Gu et al., 2015).

Late-onset sepsis is seen in infants after 72 hours of life. The infections causing late-onset sepsis are from a variety of sources, and are usually hospitalacquired infections (Simpson et al.,2016).

Neonatal sepsis describes serious bacterial or viral infections that manifest in the first 28 days of life, causing significant mortality and morbidity (National Institute for Health and Care Excellence (NICE) 2014, Bulkowstein et al 2016). Globally, in 2013, $7 \%$ of neonatal deaths were attributable to neonatal sepsis (World Health Organization 2015).

In a multi-center study in England between 2006 and 2008 incidence of neonatal infection was eight per 1,000 live births, most occurring in premature (delivered at less than 37 weeks' gestation) and low birth weight (less than 2500g) babies (Dellinger, 2015). Although neonatal age is up to the first 28 days of life, organisms that cause neonatal sepsis, such as group B Streptococcus (GBS) and Escherichia coli (E. coli) cause sepsis beyond this period and up to three months of age.

Neonates are unwell with sepsis; ED nurses should initiate airway, breathing, circulation, disability exposure assessment and ensure that administration of antibiotics is a priority while continuing resuscitation with the team. Oxygenation is often sufficient to improve respiratory and cardiac insufficiencies and is beneficial even if saturations are within normal limits at initial presentation. In very ill neonates, IV fluid resuscitation (10-20 $\mathrm{mL} / \mathrm{kg}$ of $0.9 \%$ sodium chloride) may also be required (Jones et al., 2015).

Neonates should have repeated structured assessments at least hourly and ED nurses should ensure a senior paediatric review takes place at the earliest possible time (Kirkham et al.,2014). Infants should be stabilized and monitored using NEWS or similar while they are waiting for a bed on the pediatric ward. Oral intake and urine output should also be observed (Barnden et al., 2016).

Nurses are likely to be the first health care professionals that families meet, and therefore play a vital role in providing accurate information and managing their concerns and expectations. A study of 244 parents regarding information provision on neonatal sepsis, highlighted how healthcare professionals could improve parents' experiences through better education and knowledge of the condition (Hayden et al., 2016). Health professionals should recognize that parents are likely to be scared and ED nurses are best placed to explain the situation and offer support to parents.

When parents bring a sick baby to an ED, they can feel extremely vulnerable and powerless. Sometimes senior ED nurses take on a 'parental role' for a short while, for example feeding or holding the baby in a comfortable position during blood tests or X-rays. However, this, combined with anxiety about their child, and being in an unfamiliar environment, can have negative psychological effects on parents, who report experiencing an interruption to the development of healthy parent-infant attachments and changes in their parental roles (Al Maghaireh et al., 2016). 
Nurses are ideally placed to decrease parents' stress and support them during this period of uncertainty, and throughout their child's admission to the hospital (Al Maghaireh et al., 2016).

Early detection and prompt treatment of sepsis is essential for positive long-term outcomes in infants. If untreated, mortality is $50-100 \%$, with un favorable outcomes related to low birth-weight, prematurity, respiratory distress, meningitis or low white-cell count (Damiani et al.,2015).

Neurodevelopmental disorders are associated with neonatal sepsis caused by HSV, GBS or E. coli. One study found very low birth weight infants with neonatal sepsis had increased risk of neurodevelopmental disorders (Robaina Castellanos et al., 2016), while another showed sepsis significantly contributed to neurodevelopmental disorders in extremely preterm infants (Rhodes et al., 2015). Impairments include cognitive defects, cerebral palsy, hearing loss and nephrotoxicity, which highlights how missing early signs and symptoms or risk factors for neonatal sepsis increases morbidity.

A clinical pathway, also known as care pathway, integrated care pathway, critical pathway, or care map, is one of the main tools used to manage the quality in health care concerning the standardization of care processes. It has been shown that their implementation reduces the variability in clinical practice and improves outcomes. Clinical pathways aim to promote organized and efficient patient care based on evidence-based medicine and aim to optimize outcomes in settings such as acute care and home care (Smith, 2017).

A clinical pathway(CPs) is a multidisciplinary management tool based on evidence-based practice for a specific group of patients with a predictable clinical course, in which the different tasks (interventions) by the professionals involved in the patient care are defined, optimized and sequenced either by hour (ED), day (acute care) or visit (homecare). Outcomes are tied to specific interventions (Perer,2015).

The concept of clinical pathways may have different meanings to different stakeholders. Managed care organizations often view clinical pathways in a similar way as they view care plans, in which the care provided to a patient is definitive and deliberate. Clinical pathways can range in scope from simple medication utilization to a comprehensive treatment plan. Clinical pathways aim for greater standardization of treatment regimens and sequencing as well as improved outcomes, from both a quality of life and a clinical outcomes perspective (Huang et al., 201).

The concept of clinical pathway refers to specific guidelines for care that describe patient treatment goals and define a sequence and timing of intervention for meeting those goals efficiently. They can also be defined as care plans that detail essential steps in patient care with a view to describing the expected progress of the patient. The use of clinical pathway has become very popular in the past decades in a lot of diseases and surgical procedures. pathway as designed contained the following components: assessment, consultations, rehabilitation, tests, treatments, activities, diet and nutrition, elimination, medications, education and counseling of patients and their families, and preparation for discharge(Vanhaecht et al., 2010).

Significance of the study:

According to the World Health Organization (WHO), approximately four million neonates die each year worldwide with nearly $25 \%$ to $45 \%$ of 
neonatal deaths occur caused by severe infections (2006).

In the United States, 1 to 5 of every 1000 live births results in neonatal infection. The Centers for Disease Control and Prevention (CDC) estimates that one in every 141 babies born in the United States each year dies of infection in the first year of life, with approximately 20,000 deaths in the neonatal period (2009). The incidence of neonatal infection is higher for infants with lower gestational age, with premature infants having a three to five time's greater risk of developing sepsis. Although the incidence of sepsis is relatively low, the associated morbidity and mortality is high (Holme et al., 2013).

\section{Aim of the study:}

The aim of this study was to: Determine the effect of clinical pathway on nursing care for neonates with sepsis

\section{Research Hypotheses:}

- Nursing care for neonates with sepsis significantly will be improved after implementing the clinical pathway intervention.

- Neonates with sepsis who will exposed to the clinical pathway will have negative $\mathrm{C}$ reactive protein test, improvement of feeding and decreased length of hospital stay.

\section{Subjects and method:}

\section{Research Design:}

A quasi- experimental research design was utilized.

\section{Settings:}

The study was carried out at neonatal intensive care units at Benha city as the following:

- Benha Specialized Hospital for Children affiliated to Ministry of
Health . It included two units. These units are for neonates having different diagnosis. One of them contained (14) incubators and the other unit contained (26) incubators.

- Benha University Hospital. As it include two NICUs contains (16) incubators in each unit 8 incubators.

- Benha Teaching Hospital. It includes one NICU composed of ( 15) incubators

\section{Subjects:}

\section{It consisted of two groups:}

- Group1: The first group consists of a convenient sample consists of (140) male and female nurses who are working at the above mentioned settings were taken regardless their gender and years of experience at neonatal intensive care unit more than 6 months

- Group 2: consists of a purposive sample of neonates with sepsis (140neonates) were included after fulfilling

\section{* Inclusion criteria:}

- Both sexes

- Gestational age $28 \leq 40$ weeks.-

- The current weight from $1500 \leq$ 3500 grams.

- Neonates with sepsis which manifested by the criteria

a) Early onset

b) Late onset

c) Nosocomial sepsis

\section{Exclusion criteria:}

Neonates with major malformation, congenital heart disease

\section{Tools of Data Collection:}

There were three tools utilized to collect the required data. Those tools as the following:

Tool I: A structured interviewing schedule: It was developed by the researchers after reviewing the related 
literatures and it was written in Arabic language to suit study sample. It composed of four parts

- Part (1): Assess nurses' characteristics, such as; age, gender qualifications, years of experience, attendance of training courses.

- Part (2): Assess characteristics of the studied neonates such as; gestational age, gender, current age, weight on admission and current weight.

- Part (3): Nurses' knowledge related sepsis, which includes their knowledge about; definition, causes, clinical manifestations, diagnosis and management of neonates with sepsis. The total questions were 22 and in a form of multiple choice questions.

- Part (4): Nurses` knowledge regarding nursing care of neonates with sepsis, such as; knowledge about maintenance of body temperature, proper fluid management, good nutritional support, circulation, oxygen therapy and suctioning of the neonate with sepsis, care of neonate on ventilator, blood gases estimation, prevention of nosocomial infection, medication administration and prognosis

Nurses' knowledge will be scored as following:

- Correct and complete answer was scored (2)

- Correct and incomplete answer was scored (1)

- Wrong answer or don't know and was scored (0)

The total score of nurses' knowledge were calculated and classified into three levels as following:

- $\downarrow 60 \%$ will be considered poor knowledge.

- $60-75 \%$ will be considered fair knowledge.
- 75-100 \% will be considered good knowledge.

Tool II: Clinical pathway for care of neonates with neonatal sepsis checklist:

It was adopted from (Balamuth et al.,2011). It was applied to assess daily nursing care provided to neonates with RDS inside the incubator. The total practices were 9 practices.

Scoring System for practice of the studied nurses.

Scoring system for nurse's performances will be as follows:

- Done correctly and competent will score (1)

- Done incorrect or incompetent well will score $(0)$

The total score of nurses' practice will calculated and classified as follow:

- 60 to less than 75 will be considered unsatisfactory.

- 75-100 \% will be considered satisfactory

Tool III- Neonates' medical outcomes assessment sheet: It was developed by the researchers to assess the improvement of neonates' condition after application of the clinical pathway. It included; negative CRP, feeding improvement and length of hospital stay.

\section{Preparatory phase:}




\section{Validity and Reliability}

The researchers reviewed the past, current regional and international related literatures covering all aspects of the study using textbooks, articles, journal and scientific magazines. This helped the researchers to be acquainted with the research problem and guided them in developing the study tools. To measure content validity of the study tools, the researchers assure that items of the tools were adequately represent what are supposed to measure by presented it to five experts including; three in Pediatric nursing from the Faculty of Nursing Cairo, Benha University, and two in neonatal medicine from the Faculty of medicine Benha University, to test the content validity. Modifications of the tools were done according to the experts' judgment on clarity of sentences, appropriateness of contents and sequence of items. The experts' agreed on the content, but recommended minor language changes that would make the information clearer and more precise. The suggested changes were made.

\section{Methods:}

\section{Exploratory phase:}

Ethical considerations and human rights:

An official permission to conduct the study was obtained from the hospital mangers. Then participation in the study was voluntary; each nurse was informed about the purpose, procedure, benefits, and nature of the study and each nurse had the right to withdraw from the study at any time without any rationale, then oral consent obtained from them. Subjects were informed that obtained data will not be included in any further researches. Confidentiality and anonymity of each subject was assured through coding of all data and all information has taken was protected. Pilot Study:

It was conducted on $10 \%$ of the total study sample (14 nurses) to evaluate the feasibility, reliability, and clarity of the tools .It was conducted to test the applicability of the tools, find out the possible obstacles and problems that might face the researchers and interfere with data collection. Additionally, detect any problems peculiar to the statements as sequence of questions and clarity. It was also helped to estimate the time needed for data collection, as it was 20 minutes.

\section{Field of Work:}

Data were collected from the beginning of June2017 to the beginning of December 2017. Immediately after the ethical approval was obtained; the researchers obtained oral consents from nurses who included in the study after an explanation of the aim, tools, benefits and the duration of the study to gain their cooperation. The researchers then started to interview each nurse individually and this took about 15-20 minutes for assessing knowledge. The researchers then started to assess care provided by nurses during their actual work for each neonate (routine care) 3days / week with follow up of neonates progress condition before and after the clinical pathway. The researchers were available by rotation 3 days per week: Sunday in Benha University Hospital, and Monday in the Specialized Pediatric Hospital and Tuesday in Teaching Hospital in Benha City. At the beginning of the first session, an orientation of the contents was listed and then explanation, demonstration and re demonstration were done. After finishing data collection the actual nursing care was assessed and the clinical pathway intervention applied to nurses about 
care of neonates after one or two days of admission of neonates.

\section{Procedure:}

\section{- Preparation phase:}

It was concerned with designing and testing different data collection tools, in addition, the administrative arrangements to carry out the study as well as to conduct the pilot study. In the beginning, the researchers introduce themselves to the nurses. Nurses who accept to participate in the study individually interviewed by the researchers to explain the nature, purposes, and the desired outcomes of the study and an oral consent were obtained from these nurses.

\section{Implementing phase:}

Data were collected from the beginning of June 2017 to the beginning of December 2017. The researchers were available by rotation 3 days per week: Sunday in Benha University Hospital, and Monday in the Specialized Pediatric Hospital and Tuesday in Teaching Hospital in Benha City during their working shifts (Saturday, Monday and Tuesday) in the morning and afternoon shifts by rotation in the previously mentioned study settings. Each nurse was interviewed individually for $15-20$ minutes to fill out the structured interviewing questionnaire schedule (Tool 1). The researchers clarified and answered any related questions. Then, each nurse was observed during their practice on morning and afternoon shifts using nurses observational check list by the same researcher (Tool 2). The time needed for each observation for each nurse was 20-25 minutes for three times during providing of care for neonates with sepsis.

\section{Clinical Pathway Application, Implementation, and Evaluation:}

Clinical Pathway intervention was designed based on the actual needs assessment of nurses then implemented and evaluated. The aim of this intervention was to upgrade nurses' knowledge and improve their practice regarding care of neonates with sepsis. The application of the clinical pathway intervention was carried out in the previously mentioned study settings with the studied nurses whereas, the theoretical contents were provided through three teaching sessions; each session took 20-25 minutes.

As, the contents related to sepsis (definition, causes, clinical manifestations, diagnosis and management). The studied nurses were divided into (30) groups, each group consisted of 4-5 nurses. The researchers gave each nurse a clinical pathway guidelines related to care of neonates with sepsis in addition to the teaching sessions to assure understanding and clear any misunderstanding.

Training of nurses was conducted using a laptop with MS Power Point presentations 2010 made from contents of the clinical pathway guidelines. according to working circumstances, there mental and physical readiness.

The clinical pathway intervention was implemented over three weeks period in addition to one week for pre and post-test. A time schedule suitable for nurses was developed to conduct the clinical pathway that included; date, place, topic, time and duration of each session.

At the beginning of the first session an orientation to the clinical pathway intervention and its importance and outcomes were explained. In addition, a feedback about the previous session was done and the objectives of the new topic were explained. Simple words and Arabic language were used to suite the nurses' level of understanding. At the end of each session, nurses' 
questions were discussed to correct any misunderstanding.

In addition to re-demonstration for practical procedures. As regards the practical sessions, the nurses' practices were assessed through pretest during their actual care. The pre-determined procedures before provision of any information (pretest) utilizing the clinical pathway of care of neonates with sepsis checklist, in the form of short sessions from 30-35 minutes for each practical session. The total practical sessions composed of 6 sessions divided on the nurses' groups and related to nurses' actual care of neonates with sepsis. The contents of these sessions include; proper fluid management, oxygen therapy care and ventilation, suctioning of the neonate with sepsis, care of neonate on ventilator and blood gases estimation Different teaching strategies were used for implementation of the clinical pathway intervention such as lectures, small group discussion, brain storming, role play, demonstration and redemonstration using real objects. Suitable teaching aids as booklet, colored posters, doll and real objects were prepared especially for practice. Nurses were motivated to cooperate and participate actively in different stages of the study.

\section{Administrative design:}

An official permission for data collection was obtained from the hospitals' managers through submission of official letters issued from the dean of Benha faculty of nursing. The title, objectives and outcomes of the study were illustrated as well as the main data items to be covered, and the study was carried out after gaining the necessary permission. The study was carried out during the period from beginning of June2017 to the beginning of December 2017.

\section{Statistical design:}

The collected data revised, organized, tabulated and analyzed by using SPSS (Statistical Package for the social Science Software) statistical package version 20 on IBM compatible computer. Numerical data (Quantitative data) was presented in tables by using Mean, Standard deviation $(X \pm S D)$ and analyzed by applying t-test for normally distributed variables, while qualitative data were expressed as frequency and percentage and chisquare was used. Additionally, other statistical tests such as Independent $t$ test was used as a parametric test of significance for comparison between two samples means. Pearson correlation (r) was used to measure the correlation between quantitative variables.

- P-value at .05 was used to determine significance regarding:

- P-value > $>05$ to be statistically insignificant.

- P-value $\leq 05$ to be statistically significant.

- P-value $\leq 001$ to be high statistically significant.

\section{Evaluation Phase:}

Upon the completion of the clinical pathway implementation, the posttest evaluation was conducted to evaluate the outcomes by using the same pretest tools.

\section{Results:}

Table (1) :Shows that, half of the studied nurses $(46.5 \%)$ had age between $20<25$ years with mean age of $25.03 \pm 3.92$ years, with mean years of experience was $6.05 \pm 2.36$ years. While, more than two thirds $(64.3 \%)$ of them had diploma of secondary school of nursing. Also, half of them (55.7\%) had attended training programs related to NICU.

Table (2): Represents that, the majority $(92.9 \%)$ of the studied neonates were males. While, the rest of them were females. Also, more than half $(58.6 \%)$ 
of them had current age in days of 10 $<20$ days.

Table(3) :Illustrates that, distribution of the studied nurses according to their knowledge about neonatal sepsis before and after clinical pathway implementation. As, there was an improvement in their knowledge in most items on post clinical pathway implementation phase compared with pre-clinical pathway implementation phase knowledge with high statistical significant difference ( $\mathrm{p}<0.001)$.

Table(4) :Views that, distribution of the studied nurses according to their knowledge about infection control in NICU before and after clinical pathway implementation whereas, there was a highly statistical significant difference ( $p<0.001)$ in the studied nurses' post clinical pathway implementation knowledge scores compared with preclinical pathway implementation knowledge scores regarding infection control in NICU.

Table (5): Views that, Percentage Distribution of the studied nurses according to their Practice about (immediate care) Initiate Pathway for neonatal sepsis before and after clinical pathway implementation whereas, there was a highly statistical significant difference $(\mathrm{p}<0.001)$ in the studied nurses' post clinical pathway implementation practice scores compared with pre-clinical pathway implementation practice scores regarding their nursing care of neonate with sepsis.

Table (6): Shows that, distribution of the studied nurses regarding their competent practice scores before and after the clinical pathway implementation. As, there was a statistical significant difference ( $p$ $<0.05$ ) in the studied nurses' post clinical pathway implementation practice scores compared with preclinical pathway implementation.

Table (7): Clarifies that, percentage distribution of the studied neonates regarding the effect of clinical pathway on their condition. Whereas, increased positive CRP test of the majority the studied neonates $(88.5 \%)$ before implementation of clinical pathway compared with post clinical pathway. On the other hand, more than half $(57.8 \%)$ of them had length of hospital stay less than 10 days after implementation of clinical pathway compared with the pre implementation of pathway.

Table (8): Reveals that, percentage distribution of total knowledge scores of the studied nurses about sepsis before and after clinical pathway implementation. As, more than two thirds $(65.7 \%)$ of them had poor knowledge pre-clinical pathway compared with more than three quarters(76.4\%) of them had good knowledge post clinical pathway.

Table (9): Shows that, percentage distribution of total practice scores of the studied nurses before and after clinical pathway implementation. As, more than two thirds of them(67.1.2\%) had incompetent practice pre-clinical pathway compared with $80 \%$ of them had competent practice post clinical pathway implementation.

Table (10): Shows that, highly statistical significance relations between the studied nurses' knowledge and practice and their age, educational level and years of experiences.

Table (11): Shows that, correlation between studied nurses' knowledge and practices pre and post clinical pathway implementation, it was revealed that there were a highly statistical significance correlation between them pre and post program implementation.

Table (1): Percentage Distribution of the studied nurses according to their

characteristics $($ no $=140)$ 




Table (2): Percentage Distribution of the studied neonates according to their characteristics $($ no $=140)$

\begin{tabular}{|c|c|c|c|c|}
\hline & Items & & No & $\overline{\%}$ \\
\hline $\begin{array}{c}\text { Gestational age } \\
28-<32 \text { week } \\
32-<36 \text { week } \\
36-40 \text { week } \\
\end{array}$ & & & $\begin{array}{c}8 \\
92 \\
40 \\
\end{array}$ & $\begin{array}{c}5.7 \\
65.7 \\
28.6 \\
\end{array}$ \\
\hline & Mean \pm ST. D & $34.2 \pm 2.16$ & & \\
\hline $\begin{array}{l}\text { Current age } \\
1-<10 \text { days } \\
10-<20 \text { day } \\
20-30 \text { day }\end{array}$ & & & $\begin{array}{l}27 \\
82 \\
31\end{array}$ & $\begin{array}{l}19.3 \\
58.6 \\
22.1\end{array}$ \\
\hline & Mean \pm ST. D & $14.6 \pm 6.9$ & & \\
\hline $\begin{array}{l}\text { Weight on admission } \\
1500-<2000 \text { grams } \\
2000-<2500 \text { gram } \\
2500-<3000 \text { grams } \\
3000-3500 \text { gram }\end{array}$ & & & $\begin{array}{l}68 \\
41 \\
21 \\
10\end{array}$ & $\begin{array}{c}48.6 \\
29.3 \\
157.1 \\
7.1 \\
\end{array}$ \\
\hline
\end{tabular}




\begin{tabular}{|l|c|c|}
\hline Current weight & 65 & 46.5 \\
$<2000$ gram & 44 & 31.5 \\
2000-<2500 gram & 20 & 14.2 \\
2500- <3000 gram & 9 & 6.4 \\
3000- <3500 gram & 2 & 1.4 \\
\hline$\geq 3500$ gram & \multicolumn{2}{|c|}{} \\
\hline \multicolumn{2}{|c|}{ Mean \pm ST. D $1400.2 \pm \mathbf{4 9 2 . 4}$} & \\
Sex & 76 & 54.3 \\
1-Male & 64 & 45.7 \\
2- Female & 61 & 43.6 \\
Type of birth & 79 & 56.4 \\
1-Normal & 50 & 35.7 \\
2-Cesarean Section & 50 & 35.7 \\
\hline Neonates with sepsis which manifested by the criteria & 40 & 15.6 \\
1- Early onset & $\mathbf{1 4 0}$ & $\mathbf{1 0 0}$ \\
2- Late onset & \\
3- Nosocomial & \multicolumn{2}{|c|}{} \\
\hline \multicolumn{2}{|c|}{ Total } \\
\hline
\end{tabular}

Table (3): Percentage Distribution of the studied nurses according to their knowledge about neonatal sepsis before and after clinical pathway implementation $(\mathrm{no}=140)$.

\begin{tabular}{|c|c|c|c|c|c|c|c|c|c|c|c|c|c|c|}
\hline \multirow{3}{*}{\begin{tabular}{|l} 
Nurses' \\
knowledge
\end{tabular}} & \multicolumn{6}{|c|}{ Pre-clinical pathway } & \multicolumn{6}{|c|}{ Post clinical pathway } & \multirow{3}{*}{$X^{2}$} & \multirow{3}{*}{$P$ value } \\
\hline & \multicolumn{2}{|c|}{$\begin{array}{c}\text { Complete } \\
\text { answers }\end{array}$} & \multicolumn{2}{|c|}{$\begin{array}{c}\text { Incomplete } \\
\text { answers }\end{array}$} & \multicolumn{2}{|c|}{ Don't know } & \multicolumn{2}{|c|}{$\begin{array}{c}\text { Complete } \\
\text { answers }\end{array}$} & \multicolumn{2}{|c|}{$\begin{array}{c}\text { Incomplete } \\
\text { answers }\end{array}$} & \multicolumn{2}{|c|}{ Don't know } & & \\
\hline & No & $\%$ & $\overline{\mathrm{No}}$ & $\%$ & No & $\%$ & No & $\%$ & No & $\%$ & No & $\%$ & & \\
\hline $\begin{array}{l}\text { 1-Definition of } \\
\text { neonatal sepsis }\end{array}$ & 60 & $\varepsilon r_{.} \wedge$ & 40 & YA. 0 & $\varepsilon$. & r 8.5 & $v$. & 50.0 & 0. & ro. $\mathrm{Y}$ & 20 & 14.2 & 27.13 & $\begin{array}{c}<0.001 \\
* *\end{array}$ \\
\hline $\begin{array}{l}\text { 2-Types of } \\
\text { neonatal sepsis }\end{array}$ & 10 & v.. & 30 & 41.4 & 100 & $v 1 . \varepsilon$ & 80 & ov. 1 & 30 & 41.4 & 30 & 41.4 & 35.71 & $<0.001$ \\
\hline $\begin{array}{l}\text { 3- Diagnosis of } \\
\text { neonatal sepsis }\end{array}$ & 30 & 41.4 & 90 & 64.2 & 20 & 14.2 & 80 & 57.1 & 30 & 41.4 & 30 & 41.4 & 35.71 & $<0.001$ \\
\hline $\begin{array}{l}\text { 4-Treatment of } \\
\text { neonatal sepsis }\end{array}$ & 50 & 35.7 & 60 & 42.8 & 30 & 41.4 & 90 & 64.2 & 25 & 17.8 & 25 & 17.8 & 60.35 & $<0.001 * *$ \\
\hline 5Complications & 20 & 14.2 & 40 & 28.5 & 80 & 57.1 & 60 & 42.8 & 50 & 35.7 & 30 & 41.4 & 10.00 & $<0.005^{* *}$ \\
\hline 6- Prevention & 30 & 41.4 & 90 & 64.2 & 20 & 14.2 & 100 & 71.4 & 30 & 41.4 & 10 & 7.1 & 95.71 & $<0.001 * *$ \\
\hline
\end{tabular}

Table (4): Percentage Distribution of the studied nurses according to their knowledge about infection control in neonatal intensive care unit before and after clinical pathway implementation $($ no=140). 


\begin{tabular}{|c|c|c|c|c|c|c|c|c|c|c|c|c|c|c|}
\hline \multirow{3}{*}{\begin{tabular}{|l} 
Nurses' \\
knowledge
\end{tabular}} & \multicolumn{6}{|c|}{ Pre-clinical pathway } & \multicolumn{6}{|c|}{ Post clinical pathway } & \multirow[t]{3}{*}{$\mathbf{X}^{2}$} & \multirow[t]{3}{*}{$P$ value } \\
\hline & \multicolumn{2}{|c|}{$\begin{array}{c}\text { Complete } \\
\text { answers }\end{array}$} & \multicolumn{2}{|c|}{$\begin{array}{c}\text { Incomplete } \\
\text { answers }\end{array}$} & \multicolumn{2}{|c|}{ Don't know } & \multicolumn{2}{|c|}{$\begin{array}{c}\text { Complete } \\
\text { answers }\end{array}$} & \multicolumn{2}{|c|}{$\begin{array}{l}\text { Incomplete } \\
\text { answers }\end{array}$} & \multicolumn{2}{|c|}{$\begin{array}{l}\text { Don't } \\
\text { know }\end{array}$} & & \\
\hline & No & $\%$ & No & $\%$ & No & $\%$ & No & $\%$ & No & $\%$ & No & $\%$ & & \\
\hline $\begin{array}{l}\text { 1-Sterilization } \\
\text { of incubator }\end{array}$ & 58 & 41.4 & 61 & 43.5 & 21 & 15.0 & 126 & 90.0 & 8 & 5.7 & 6 & 4.2 & 202.31 & $<0.001 * *$ \\
\hline $\begin{array}{l}\text { 2- Disinfected } \\
\text { of incubator }\end{array}$ & 81 & 757.8 & 42 & 30.0 & 17 & 12.1 & 103 & 73.5 & 22 & 15.7 & 15 & 10.7 & 102.52 & $<0.001 * *$ \\
\hline $\begin{array}{l}\text { 3- Sterilization } \\
\text { of tube of } \\
\text { CPAP }\end{array}$ & 35 & 25.0 & 95 & 67.8 & 10 & 7.1 & 105 & 75.0 & 20 & 14.2 & 15 & 10.7 & 109.64 & $<0.001 * *$ \\
\hline $\begin{array}{lr}4- & \text { Disinfected } \\
\text { of } & \text { neonate } \\
\text { umbilical cord }\end{array}$ & 95 & 67.8 & 25 & 17.8 & 20 & 14.2 & 130 & 92.8 & 5 & 3.5 & 5 & 3.5 & 223.22 & $<0.001 * *$ \\
\hline $\begin{array}{l}\text { 5- Disinfected } \\
\text { of neonate eyes }\end{array}$ & 104 & 74.2 & 25 & 17.8 & 11 & 7.8 & 118 & 84.2 & 20 & 14.2 & 2 & 1.4 & 167.02 & $<0.001 * *$ \\
\hline $\begin{array}{l}\text { 6- change of IV } \\
\text { cannula }\end{array}$ & 50 & 35.7 & 73 & or. 1 & 17 & 12.1 & 109 & VY.A & $r$. & r). & 1 & $\cdot{ }^{v}$ & 133.90 & $<0.001 * *$ \\
\hline
\end{tabular}

Table (5): Percentage Distribution of the studied nurses according to their

Practice about (immediate care) Initiate Pathway for neonatal sepsis before and after clinical pathway implementation (no=140).

\begin{tabular}{|c|c|c|c|c|c|c|c|c|c|c|}
\hline \multirow{3}{*}{$\begin{array}{l}\text { Nurses' } \\
\text { knowledge }\end{array}$} & \multicolumn{4}{|c|}{ Pre-clinical pathway } & \multicolumn{4}{|c|}{ Post clinical pathway } & \multirow{3}{*}{$\mathbf{X}^{2}$} & \multirow{3}{*}{$P$ value } \\
\hline & \multicolumn{2}{|c|}{ Done } & \multicolumn{2}{|c|}{ Not done } & \multicolumn{2}{|c|}{ Done } & \multicolumn{2}{|c|}{ Not done } & & \\
\hline & No & $\%$ & No & $\%$ & No & $\%$ & $\overline{\text { No }}$ & $\%$ & & \\
\hline $\begin{array}{l}\text { 1- Pathway for neonate } \\
\text { : Within first } 10 \text { minutes }\end{array}$ & 30 & Y). & 110 & 78.5 & 88 & 62.8 & 52 & 37.1 & 9.25 & $<0.05^{*}$ \\
\hline $\begin{array}{l}\text { 2- Pathway for neonate } \\
\text { : Within first } 20 \text { minutes }\end{array}$ & 47 & rT. & 93 & $77 . \varepsilon$ & 96 & 71.0 & 44 & 31.4 & 19.41 & $<0.001 * *$ \\
\hline $\begin{array}{l}\text { 3- Pathway for neonate } \\
\text { : Within first } 40 \text { minutes }\end{array}$ & 51 & 36.4 & 89 & 63.5 & 99 & 70.7 & 41 & 29.2 & 24.02 & $<0.001 * *$ \\
\hline $\begin{array}{l}\text { 4- Pathway for neonate } \\
\text { : Within first } 60 \text { minutes }\end{array}$ & 33 & 23.5 & 107 & 76.4 & 102 & 72.8 & 38 & 27.1 & 29.25 & $<0.001 * *$ \\
\hline
\end{tabular}

Table (6): Distribution of the studied nurses regarding their competent practice scores before and after the clinical pathway implementation $(\mathrm{No}=140)$ 


\section{Number of Studied Nurses $=(140)$}

Competent practice

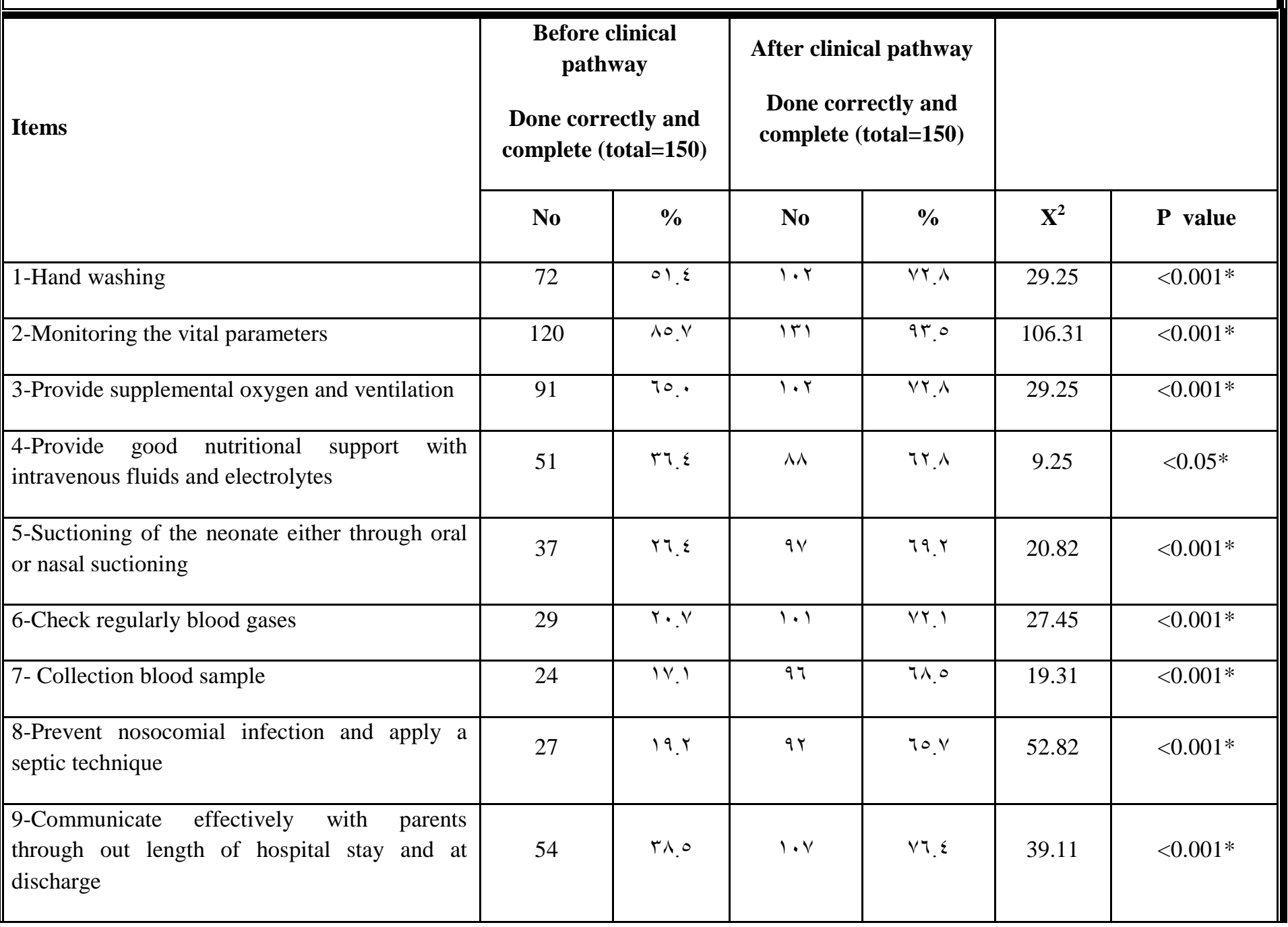

Table (7): Percentage distribution of the studied neonates regarding effect of Clinical Pathway on their condition $(\mathrm{No}=140)$

\begin{tabular}{|c|c|c|c|c|c|c|}
\hline \multicolumn{7}{|c|}{ Number of the Studied neonates $=(140)$} \\
\hline \multirow{2}{*}{ Items } & \multicolumn{2}{|c|}{$\begin{array}{l}\text { Before application of } \\
\text { the clinical pathway }\end{array}$} & \multicolumn{2}{|c|}{$\begin{array}{l}\text { After application of the } \\
\text { clinical pathway }\end{array}$} & \multirow[b]{2}{*}{$\mathbf{X}^{2}$} & \multirow[b]{2}{*}{$P$ value } \\
\hline & No & $\%$ & No & $\%$ & & \\
\hline \multicolumn{5}{|l|}{ Feeding improvement } & \multirow{3}{*}{ TV.YO } & \multirow{3}{*}{$<0.001^{*}$} \\
\hline Normal & 7. & $\varepsilon r . \wedge$ & 101 & $\left.V T_{.}\right)$ & & \\
\hline Hypoactive/ hyperactive & 80 & ov.1 & 39 & $r V_{. \wedge}$ & & \\
\hline
\end{tabular}




\begin{tabular}{|c|c|c|c|c|c|c|}
\hline \multicolumn{5}{|l|}{ CRP test } & \multirow{3}{*}{71.42} & \multirow{3}{*}{$<0.001 *$} \\
\hline Positive & $M \varepsilon$ & 11.0 & 20 & $1 \leqslant . r$ & & \\
\hline Negative & 16 & $11 . \varepsilon$ & 120 & 10. V & & \\
\hline \multicolumn{5}{|c|}{ Length of hospital stay in days } & \multirow{4}{*}{52.55} & \multirow{4}{*}{$<0.001^{*}$} \\
\hline $10-$ & 10 & v. 1 & 81 & ov.A & & \\
\hline $20-$ & 55 & rq. & 48 & $r \leqslant . r$ & & \\
\hline$\geq 30$ & 75 & or.o & 11 & $\vee . \wedge$ & & \\
\hline
\end{tabular}

Table 8:- Percentage distribution of total knowledge scores of the studied nurses about neonatal sepsis before and after clinical pathway implementation(No=140)

\begin{tabular}{|c|c|c|c|c|c|c|}
\hline \multirow{2}{*}{ Level of knowledge } & \multicolumn{2}{|c|}{$\begin{array}{c}\text { Nurses' knowledge before } \\
\text { clinical pathway }\end{array}$} & \multicolumn{2}{|c|}{$\begin{array}{l}\text { Nurses' knowledge after } \\
\text { clinical pathway }\end{array}$} & \multirow{2}{*}{$X^{2}$} & \multirow{2}{*}{$P$ value } \\
\hline & No & $\%$ & No & $\%$ & & \\
\hline $\begin{array}{l}\text { Good } \\
(75-100 \%)\end{array}$ & 14 & 10.0 & 107 & 76.4 & & \\
\hline $\begin{array}{l}\text { Average } \\
(60-75 \%)\end{array}$ & 34 & 24.2 & 20 & 14.2 & 117.52 & $<0.001$ \\
\hline $\begin{array}{l}\text { Poor } \\
(<60 \%)\end{array}$ & 92 & 65.7 & 13 & 9.2 & & \\
\hline
\end{tabular}

Table (9):Percentage distribution of total practice scores of the studied nurses before and after clinical pathway implementation $(\mathrm{No}=140)$

\begin{tabular}{|c|c|c|c|c|c|c|}
\hline \multirow[t]{2}{*}{ Level of performance } & \multicolumn{2}{|c|}{$\begin{array}{c}\text { Nurses' performance } \\
\text { before clinical } \\
\text { pathway }\end{array}$} & \multicolumn{2}{|c|}{$\begin{array}{l}\text { Nurses' performance after } \\
\text { clinical pathway }\end{array}$} & \multirow[t]{2}{*}{$\mathbf{X}^{2}$} & \multirow[t]{2}{*}{$P$ value } \\
\hline & No & $\%$ & No & $\%$ & & \\
\hline $\begin{array}{l}\text { Competent } \\
(>75 \%) \\
\text { Incompetent } \\
(<75 \%)\end{array}$ & 46 & 32.8 & 112 & 80.0 & 50.40 & $<0.001$ \\
\hline
\end{tabular}


Table (10): Relation between studied nurses' knowledge and practices and with their characteristics $(\mathrm{No}=140)$

\begin{tabular}{|c|c|c|c|c|c|c|c|}
\hline \multirow{2}{*}{ Personal data } & \multicolumn{2}{|c|}{ Knowledge } & \multicolumn{2}{|c|}{ ANOVA } & \multirow{2}{*}{$\begin{array}{l}\text { Practice } \\
x \pm S D\end{array}$} & \multicolumn{2}{|l|}{ ANOVA } \\
\hline & $\begin{array}{l}\text { N0: } \\
150\end{array}$ & $\mathrm{x} \pm \mathrm{SD}$ & $\begin{array}{l}\text { F/T } \\
\text { test }\end{array}$ & $P$ value & & $\begin{array}{l}\text { F/T } \\
\text { test }\end{array}$ & $P$ value \\
\hline \multicolumn{8}{|l|}{ Age in years } \\
\hline$-<20$ & 5 & $0.00 \pm 0.00$ & \multirow{4}{*}{$\begin{array}{l}\mathrm{F} \text { test } \\
35.10\end{array}$} & \multirow{4}{*}{$<0.001$} & $0.00 \pm 0.00$ & \multirow{4}{*}{$\begin{array}{l}\mathrm{F} \text { test } \\
22.99\end{array}$} & \multirow{4}{*}{$0.001^{* *}$} \\
\hline$-20-<25$ & 65 & $1.44 \pm 0.74$ & & & $0.64 \pm 0.48$ & & \\
\hline$-25-<30$ & 50 & $2.00 \pm 0.00$ & & & $1.00 \pm 0.00$ & & \\
\hline$-\quad \geq 30$ & 20 & $2.00 \pm 0.00$ & & & $1.00 \pm 0.00$ & & \\
\hline \multicolumn{8}{|l|}{ Gender } \\
\hline Male & 10 & $1.07 \pm 0.25$ & \multirow{2}{*}{$\begin{array}{l}\text { T test } \\
49.049\end{array}$} & \multirow{2}{*}{$<0.001$} & $1.07+0.25$ & \multirow{2}{*}{$\begin{array}{l}\text { T test } \\
23.58\end{array}$} & \multirow{2}{*}{$<0.001$} \\
\hline Female & 130 & $1.67 \pm 0.63$ & & & $0.80+0.40$ & & \\
\hline \multicolumn{8}{|l|}{ Educational level } \\
\hline $\begin{array}{l}\text { Diploma of } \\
\text { secondary nursing } \\
\text { school }\end{array}$ & 90 & $1.48 \pm 073$ & \multirow{3}{*}{$\begin{array}{l}\text { F test } \\
11.86\end{array}$} & \multirow{3}{*}{0.00} & $0.68 \pm 0.46$ & \multirow{3}{*}{$\begin{array}{l}\text { F test } \\
11.04\end{array}$} & \multirow{3}{*}{$<0.001^{* *}$} \\
\hline $\begin{array}{l}\text { Diploma of } \\
\text { Technical } \\
\text { institute } \\
\text { nursing }\end{array}$ & 40 & $2.00 \pm 0.00$ & & & $1.00 \pm 0.00$ & & \\
\hline $\begin{array}{l}\text { Bachelor degree } \\
\text { in nursing science }\end{array}$ & 10 & $2.00 \pm 0.00$ & & & $1.00 \pm 0.00$ & & \\
\hline \multicolumn{8}{|l|}{ Years of experience } \\
\hline$<3$ & 5 & $0.00 \pm 0.00$ & \multirow{3}{*}{$\begin{array}{l}\text { F test } \\
39.49\end{array}$} & \multirow{3}{*}{$<0.001$} & $0.0 \pm 0.00$ & \multirow{3}{*}{$\begin{array}{l}\text { F test } \\
26.26\end{array}$} & \multirow{3}{*}{$<0.001^{* *}$} \\
\hline $3<6$ & 60 & $1.40 \pm 0.71$ & & & $0.61 \pm 0.41$ & & \\
\hline $6<9$ & 55 & $2.00 \pm 0.00$ & & & $1.00 \pm 1.00$ & & \\
\hline$\geq 9$ & 20 & $02.00 \pm 0.00$ & & & $1.00 \pm 1.00$ & & \\
\hline
\end{tabular}

Table (11): Correlation between Total Knowledge and Total practice Pre and Post Clinical Pathway implementation (140) 


\begin{tabular}{|l|l|l|l|l||}
\hline \multirow{2}{*}{ Items } & \multicolumn{3}{|l|}{$\begin{array}{l}\text { Pre clinical } \\
\text { pathway (150) }\end{array}$} & \multicolumn{2}{l|}{$\begin{array}{l}\text { Post clinical } \\
\text { pathway(150) }\end{array}$} \\
\cline { 2 - 5 } & R & $\mathbf{p}$ & $\mathbf{r}$ & $\mathbf{p}$ \\
\hline Knowledge & 0.902 & $0.000^{* *}$ & 0.952 & $0.000^{* *}$ \\
\hline Practice & 0.891 & $0.000^{* *}$ & 0.912 & $0.000^{* *}$ \\
\hline
\end{tabular}

\section{Discussion}

Sepsis is a widespread bacterial infection in the blood circulation. It is also referred to as septicemia. Infants are at high risk of infection due to their low and immature immune system. The newborn has a poor response to pathogens and the local inflammatory reaction that signals the presence of an infection at the entry site is usually absent, which results in non-specific and broad symptoms(Robinson et al.,2016).

Clinical pathways have been developed in health care as multidisciplinary care plans that outline the sequence and timing of actions necessary for achievement of expected patient outcomes and organizational goals regarding quality, costs, patient satisfaction and efficiency. Additionally, the concept of clinical pathway refers to specific guidelines for care which describe patient treatment goals and define the sequence and timing of intervention for meeting those goals efficiently. So, the aim of this study was to evaluate the effect of clinical pathway on enhancing nursing care of neonates with sepsis(Weber et al., 2017).

Regarding personal data of the studied nurses, the results of the present study revealed that, the mean age of the studied nurses was $(25.03 \pm 3.92)$.This may be attributed to the lack of nurses' knowledge .This result was similar to the results of study by ( Mustafa, 2007), who found in her study that age groups of nurses were between $20-<25$ year.

As regard the years of experience of the studied nurses, the finding of the current study showed that, mean years of experiences was $6.05 \pm 2.36$ years, this finding were similar to the finding of ( Kunswa, 2006 ), who found that the majority of studied nurses had years of experience ranged from 5-10 years with mean $5.5 \pm 3.01$ years.

On studying the academic qualification of nurses, it was observed in the present study that, more than two thirds $(64.3 \%)$ had nursing diploma (secondary school), this may be due to the fact that nursing secondary school provide the community with large number of graduate diploma nurses than other agencies such as faculties of nursing and technical nursing institutes, these findings were similar to the finding of

(Mohammed, 2010), the majority of studied nurses ( $88.6 \%$ ) had nursing diploma (secondary school.

Regarding to characteristics of the studied neonates with sepsis, the present study found that, the mean gestational age was $34.2 \pm 2.16$ weeks and the mean weight of neonates on admission was $1243.2 \pm 484.8$. While, gender of the studied neonates, the current study showed that the majority of neonates showed that the majority of neonates ( $54.3 \%$ ) were males. This finding was supported by Mohamed (2010), who found that, the 
mean gestational age was32.4 \pm 2.44 , who found that, more than half of neonates $(54.3 \%)$ were males.

In relation to knowledge of the studied nurses, it is obvious from the current study that, the total knowledge scores post clinical pathway implementation about neonatal sepsis had significant differences towards definition of neonatal sepsis, leading causes, diagnosis, prevention and treatment compared with pre-clinical pathway implementation knowledge scores. This result is supported by Amin,(2004) who reported a higher increase in study group subjects' knowledge mean scores immediately post nursing clinical pathway implementation than before, with a highly significant statistical differences. From the researchers' points of view this may due to lack of training courses related to neonatal nursing care.

The current study revealed that, there was a high statistical significant difference $(\mathrm{P}<0,001)$ among nurses competent practices regarding nursing care of neonates with sepsis before and after applying clinical pathway. This is in accordance with Mahmoud and Abd-El Sadik, ( 2013) who found that an obvious improvement in practice scores of the study group subjects immediately post nursing clinical pathway implementation than prenursing clinical pathway implementation.

Regarding the effect of clinical pathway on the studied neonates. The current study revealed that, there was an obvious improvement of neonates' condition. Whereas, more than half of them had length of hospital stay less than 10 days after application of clinical pathway compared with the pre application of pathway. Additionally, the majority of them had negative CRP test after application of clinical pathway compared with the pre application of pathway. This may be due to the effect of newly techniques in application of care especially critically ill neonates. This was in accordance with (Abdel Sadik and Mostafa 2016) who found that, in their study that their findings improving respiratory signs and/or symptoms and decreasing o2 daily requirements, and these were common criteria for early switch and early signs for neonates' discharge from hospital.

\section{Conclusion:}

Based on the findings of this study, we can conclude that:

Implementation of the nursing clinical pathway is highly effective method to improve nurses' knowledge and can enhancing nursing care of neonates with sepsis by raising nurses' knowledge, enhancing their practice, improved neonatal outcomes and reduces their length of hospital stay.

\section{Recommendations:}

Based on the results of the current study, the following

recommendations were reached:

- Clinical pathway on nursing care of neonates with sepsis should be applied for neonates with sepsis in different settings

- Provision of regular training programs for nurses about care of neonates with sepsis on a wider scale in similar settings to further 
confirm its utility and benefits in improving nurses' knowledge and practice.

- The clinical pathway approach of care can be generalized for utilization by health team members in different pediatric healthcare settings.

\section{References:-}

Abdel Sadik and Mostafa 2016: Effect of Using Clinical Pathway on Nursing Care of Neonates with Respiratory Distress Syndrome.

Al Maghaireh D, Abdullah K and Chan C (2016): Systematic review of qualitative studies exploring parental experiences in the neonatal intensive care unit. Journal of Clinical Nursing. 25, 19-20, 2745-2756.

Amin, F.M. Intervention Nursing Program for Care of High Risk Neonate at Mansoura Hospitals, Doctorate thesis, Faculty of Nursing, Ain Shams University, Egypt. 2004

Balamuth, F., MD; Funari, RN; J. Lavelle, MD; C. Jacobstein, MD; D. Davis, MD; J. Fitzgerald, MD J. Gerber, MD; T. Metjian, Pharm D; S. Fesnak, MD; L. Hutchins, CRNP; D and Potts, RN(2011): ED Pathway for Evaluation/Treatment of Infants > 28 Daysof Age and Children with Severe Sepsis.

Barnden $\mathrm{J}$, Allen $\mathrm{V}$ and Heaton $\mathrm{P}$ (2016): Sepsis in early infancy: recognition and nursing management. Nursing Children and Young People. 28, 10, 36-44.
Casserly B, Phillips GS and Schorr C(2015): Lactate measurements in sepsis-induced tissue hypoperfusion: results from the Surviving Sepsis Campaign database. Crit Care Med 2015; 43:567-573.

Dellinger RP(2015): Foreword. The Future of Sepsis Performance Improvement. Crit Care Med 2015; 43:1787-1789.

Gu WJ, Zhang Z and Bakker J(2015): Early lactate clearance-guided therapy in patients with sepsis: a meta-analysis with trial sequential analysis of randomized controlled trials. Intensive Care Med 2015; 41:1862- 1863.

Holme H, Bhatt R, Koumettou M (2013): Retrospective evaluation of a new neonatal trigger score. Pediatrics. 131, 3, e837-842.

Huang, Z; Dong, Wei; J, L; Gan, C and Lu, X, (February 2014): "Discovery of clinical pathway patterns from event logs using probabilistic topic models". Journal of Biomedical Informatics. 47: 3957. doi:10.1016/j.jbi.2013.09.003 .PMID 24076435.

Jones SL, Ashton CM and Kiehne L(2015): Reductions in Sepsis Mortality and Costs After Design and Implementation of a NurseBased Early Recognition and Response Program. Jt Comm J Qual Patient Saf 2015; 41:483491.

Kirkham E, Heaton $\mathrm{P}$ and Paul S (2014): At a glance: neonatal sepsis in the community. Journal of Family Health Care. 24, 7, 17 18, 20-21.

Kunswa, A, M., (2006): Needs, Problems and Nursing Care of Newborn Infants, Doctorate 
Thesis, Faculty of Nursing, Ain Shams University, pp:118- 124.

Mahmoud, F.S. and Abd-ElSadik B.R. (2013): Effect of clinical pathway regarding promoting quality nursing care of children with meningitis exposed to invasive procedures. Journal of American Science, 2013; 9(8)383-393.

Mohamed, S.(2010): Quality of Nursing Care for Neonates with Respiratory DistressSyndrome outcomes master thesis, Faculty of Nursing, Benha University. 2010

Moustafa, S.,(2007):- Quality of Nurses Performance In Neonatal Intensive Care Units, Master Thesis, Faculty of Nursing, Benha University, Egypt.

National Institute for Health and Care Excellence (2016): Sepsis Recognition, Diagnosis, and Early Management. www.nice.org.uk/guidance/ng51/ resources/sepsis-recognitiondiagnosis-and-earlymanagement-1837508256709 (Last accessed: 13 September 2017.)

Perer, A; Wang, $\mathrm{F}$ and $\mathrm{Hu}, \mathrm{J}$ (August 2015): "Mining and exploring care pathways from electronic medical records with visual analytics". Journal of Biomedical Informatics. 56: 369378. doi:10.1016/j.jbi.2015.06.02 0. PMID 26146159.

Rhodes A, Phillips $G$ and Beale $R(2015)$ : The Surviving Sepsis Campaign bundles and outcome: results from the International Multicentre Prevalence Study on Sepsis (the IMPreSS study). Intensive Care Med 2015; 41:1620-1628.
Robaina, C, G and Riesgo, R, S (2016): Neonatal sepsis and neurodevelopment in very low birth weight infants in Matanzas, Cuba 2006-2010: a prospective cohort study. Medwave. 16, 3, e6422.

Robinson, D; Kumar, P and Cadichon, S (2016): Neonatal sepsis in the emergency department. Clinical Pediatric Emergency Medicine. 9, 160-168.

Simpson, SQ; Gaines, $M$ and Hussein, Y (2016): Early goal-directed therapy for severe sepsis and septic shock: A living systematic review. J Crit Care 2016; 36:4348.

Smith, S, R. (June 2017): "Enlisting patient and family advisers in the design of clinical pathways". Journal of Healthcare Management. 62 (3):160 165. doi:10.1097/JHM-D-1 00045. PMID 28471851.

Vanhaecht, K; Panella, M; Van Zelm, $\mathrm{R} ; \mathrm{S}$ and Walter,S (September 2010): "An overview on the history and concept of care pathways as complex interventions". International Journal of Care Pathways. 14 (3): 117-123. doi:10.1258/jicp.2010.010019.

Weber, P; Filho, J; Bosco, F; Bordbar, B; Lee, M; Litchfield, I and Backman, R (October 2017): "Automated conflict detection between medical care pathways". Journal of Software: Evolution and Process. 56: 369-378.

World Health Organization (2015) World Health Statistics 2015: Part II Global Health Indicators. www.who.int/gho/publications/w orld_health_statistics/EN_WHS2 
015_Part2.pdf?ua=1

(Last accessed: 13 September 2017.)

Bulkowstein S, Ben-Shimol S, GivonLavi N (2016) :Comparison of early onset sepsis and community-acquired late onset sepsis in infants less than three months of age. BMC Pediatrics. $16,1,82$.

Consensus Definitions for Sepsis and Septic Shock (Sepsis-3). JAMA 2016; 315:801-810.

Damiani E, Donati A and Serafini G(2015):: Effect of performance improvement programs on compliance with sepsis bundles and mortality: a systematic review and meta-analysis of observational studies. PLoS One 2015; 10:e0125827.

Hayden GE, Tuuri RE and Scott $R$ (2016): Triage sepsis alert and sepsis protocol lower times to fluids and antibiotics in the ED.
Am J Emerg Med. 2016;34(1):19.

National Institute for Health and Care Excellence (2014): Neonatal Infection, Quality Standard 75. www.nice.org.uk/guidance/qs 75/r esources/neonatal-infection2098849787845 (Last accessed: 13 September 2017.)

Shankar-Hari M, Phillips GS and Levy ML(2016); Sepsis Definitions Task Force: Developing a New Definition and Assessing New Clinical Criteria for Septic Shock: For the Third International Consensus Definitions for Sepsis and Septic Shock (Sepsis-3). JAMA 2016; 315:775-787.

Singer M, Deutschman CS and Seymour CW (2016): The Third International Consensus Definitions for Sepsis and Septic Shock (Sepsis-3). JAMA 2016; 315:801-810. 